\title{
LA POESÍA DEL LENGUAJE. EN TORNO A LA CREATIVIDAD DE LAS
} PALABRAS

\author{
The poetry of language. Regarding the creativity of words
}

\author{
SERGIO MANSILLA TORRES \\ Universidad Austral de Chile (Chile) \\ sergio.mansilla@uach.cl
}

\section{Resumen}

En el presente ensayo se expone y discute la idea de que el lenguaje, más allá de ser un medio de comunicación, se manifiesta como poesía; esto en el sentido de que es en el lenguaje (y gracias a él) donde diariamente se configura el mundo con sentido humano. Poesía del lenguaje aparece como una expresión que busca dar cuenta de la energía creadora del lenguaje a la hora de instituir la realidad en la dimensión lingüística de esta. La discusión toma la forma de comentarios y diálogo con tesis de pensadores como Heidegger, Saussure, Benjamin, Maturana, y de poetas como Novalis, Neruda, Huidobro, con el propósito de elucidar la dimensión poética del lenguaje y sus efectos prácticos y morales en la vida social.

Palabras claves: Poesía del lenguaje; creatividad; poiesis lingüística; ser y poesía.

\section{Abstract}

In this essay we explain and discuss the idea that language, beyond its quality of being a means of communication, manifests itself as poetry; in the sense that it is in language (and thanks to it) where the daily configuration of a world with human meaning takes place. The poetry of language appears as an expression that thrives to explain the creative energy of language, as it institutes reality in its linguistic dimension. The discussion take shape in the form of comments on, and dialogue with, thinkers such as Heidegger, Saussure, Benjamin, Maturana, and with poets such as Novalis, Neruda, Huidobro, with the purpose of elucidating the poetic dimension of language and its practical and moral effects on social life.

Key words: Poetry of language; creativity; linguistic poiesis; being and poetry

\section{INTRODUCCIÓN}

"El lenguaje es el más peligroso de los bienes", sentenció Heidegger en su célebre conferencia de 1936 "Hölderlin y la esencia de la poesía". La tesis, como sabemos, no pertenece a Heidegger, en realidad, sino al propio poeta que el filósofo comenta, algo que Heidegger deja meridianamente claro en un gesto que, estimo, viene a reconocer que, a la hora de pensar el poder alumbrante del lenguaje ante la oscuridad del mundo, la poesía siempre va por delante de la filosofía. Poder que, digámoslo de entrada, no busca ordenar de forma racional, con arreglo a fines pragmáticos, la "casa del ser" (Heidegger dixit), sino decirla y en última instancia constituirla en el lenguaje atestiguando el, digamos, 
inextricable caos de esta; caos desde donde emana, sin embargo, la potencia del ser y del existir. Acerca de este singular "desorden" de la poesía, Novalis no deja lugar a dudas:

Mientras el filósofo se limita a ordenar todo, el poeta deshace todo bando. Sus palabras no son signos generales; son tonos, palabras mágicas que movilizan bellos grupos a su alrededor. Tal como los atavíos de los santos conservan virtudes maravillosas, así una palabra se vuelve casi un poema mediante un recuerdo glorioso que la santifica. Para el poeta el lenguaje nunca es demasiado pobre, pero siempre es muy general. A menudo requiere palabras recurrentes, tomadas del uso. Su mundo es simple, como un instrumento, pero asimismo inagotable en melodías (Novalis, 2017, p. 11).

Quisiera en lo inmediato retener la idea de Novalis relativa a que para el poeta "el lenguaje nunca es demasiado pobre, pero siempre es muy general" y conectarla, de alguna manera a lo largo de este escrito, con las aseveraciones de Heidegger acerca del peligro que entraña el lenguaje: "Es el lenguaje -dice el filósofo- el que crea ante todo el campo en que puede ser amenazado el ser; esto significa peligro" (Heidegger, 1944, p. 16). Y a renglón seguido agrega: "Por el lenguaje puede expresarse lo que hay de más puro y de más recóndito, tanto como lo más confuso y lo más común” (p. 16). Inquirir acerca de la naturaleza de aquello que presuntamente sería "puro" y "recóndito", en oposición a aquello que sería "confuso" y "común", puede resultar una tarea ardua sin garantías de éxito y con el riesgo de que termine, además, insistiendo en la defensa de una versión idealizada de la poesía. Versión que implicaría, por ejemplo, suponer que en ella no habría espacio sino para las sublimes bellezas de un mundo ajeno a las impurezas y monstruosidades de la vida. Me seduce, en cambio, pensar que es en la poesía, precisamente, donde las impurezas del mundo se vuelven significativas, entendamos: desbordan su condición primaria de "impurezas", pues habitan, hacen presencia iluminadora, en el lenguajeo poético, el cual, como lo sugiere Novalis, se vale a menudo de "palabras recurrentes, tomadas del uso". 1

$\mathrm{Al}$ respecto, y a modo de excurso, quizás venga a cuento recordar la posición de Neruda en lo referente a una poesía sin pureza:

Una poesía impura como un traje, como un cuerpo, con manchas de nutrición, y actitudes vergonzosas, con arrugas, observaciones, sueños, vigilia, profecías,

\footnotetext{
${ }^{1}$ Me apropio del verbo lenguajear con el que Humberto Maturana, biólogo y filósofo chileno, en diversos trabajos suyos, da cuenta del carácter dinámico y relacional del lenguaje. La obra de Maturana es vasta. En la línea de la discusión que aquí se desarrolla, el lector podría revisar su ya clásico libro La realidad, ¿objetiva o construida? Fundamentos biológicos de la realidad. V. 1 y V. 2 de 1995 y 1996, respectivamente. Dejo constancia de que el fluir conceptual y emotivo de estas notas, se acerca a la perspectiva de Maturana en el terreno de lo que me atrevería a llamar "afinidad de sentir" en torno al lenguaje.
}

244 | Alpha No50 (Julio 2020) PÁGS. 243-262. ISSN 07 16-4254 
declaraciones de amor y de odio, bestias, sacudidas, idilios, creencias políticas, negaciones, dudas, afirmaciones, impuestos.

La sagrada ley del madrigal y los decretos del tacto, olfato, gusto, vista, oído, el deseo de justicia, el deseo sexual, el ruido del océano, sin excluir deliberadamente nada, sin aceptar deliberadamente nada, la entrada en la profundidad de las cosas en un acto de arrebatado amor, y el producto poesía manchado de palomas digitales, con huellas de dientes y hielo, roído tal vez levemente por el sudor y el uso. Hasta alcanzar esa dulce superficie del instrumento tocado sin descanso, esa suavidad durísima de la madera manejada, del orgulloso hierro. La flor, el trigo, el agua tienen también esa consistencia especial, ese recuerdo de un magnífico tacto (Neruda, 1935). ${ }^{2}$

Disculpará el lector lo extenso de la cita, pero vale como una forma de insistir en que cuando hablamos de poesía y del lenguaje (o lenguajes) en el que ella se funda, emergen, como es de esperar, visiones encontradas que delatan diferencias de concepciones de lo poético. Considerar que el lenguaje de la poesía documenta la realidad de la vida material cotidiana, con sus grandezas y pequeñeces varias y que esto, además, es una manera de hacer que la poesía sea parte de esa misma cotidianidad nada sublime, es el camino que elige Neruda. Un camino alterno sería considerar que el lenguaje de la poesía abre un registro otro del mundo en el que lo "confuso" y "lo más común", quedan cancelados en beneficio de significaciones que escaparían de las que emergen del uso recurrente y común del lenguaje y que, entonces, transportarían al poeta y a sus lectores (u oyentes) a un espacio ontológico signado por la "pureza" que se haría presente en el decurso de las metáforas.

Si bien la disyunción que planteo ilustra tendencias poéticas divergentes, llevadas estas a sus puntos límites, el asunto no tiene que verse por fuerza como una oposición inconciliable. El propio Neruda estaría de acuerdo con Heidegger en lo que concierne al hecho de que la poesía lo que hace es construir presencia de lo recóndito de las cosas, verbalizando atributos inesperados y sorprendentes de estas; atributos que hallan lugar justamente en el juego de significaciones que las metáforas echan a rodar. Como el mismo Neruda sugiere, es en la escena de la poesía en que los elementos -las materias (estamos viendo el tamaño adecuado de los guiones, en las normas editoriales) primigenias-se nos manifiestan con un "magnífico tacto", con "suavidades durísimas" y "dulce superficie". Como fuere, por lo pronto quedémonos con la idea de que la poesía comporta una extrañeza lingüística y discursiva que genera un cúmulo de asociaciones y emociones varias que no obedecen ni a pretensiones comunicativas pragmáticas, ni a

\footnotetext{
2 "Sobre una poesía sin pureza" es un manifiesto que Neruda publicó en 1935 en la revista Caballo Verde para La Poesía, Nro. 1, octubre de dicho año, revista de la que el propio Neruda era su director. Cito de una versión en línea.
} 
modelos lógicos de razonamiento conducentes a la sustentación de alguna tesis. Si esa extrañeza se endilga hacia la pureza y lo recóndito del espíritu humano o hacia las impurezas cotidianas y materiales del vivir, ajenas a idealizaciones hieráticas, es ya más un asunto de poetas que de filósofos; más de prácticas poéticas concretas que de presuntos atributos estables de la poesía que determinarían su "esencia", por decirlo en el registro heideggeriano.

El propósito que anima estas reflexiones, sin embargo, no es elucidar la naturaleza del lenguaje poético - aspecto en el que han corrido ríos de tinta-ni menos determinar la "esencia de la poesía", punto en que Heidegger sí tiene mucho que decir. Mi empeño avanza en otra dirección: exponer, comentar, revisitar algunas ideas acerca de aquello que para efectos de este escrito llamaré la "poesía del lenguaje". Expresión que no es sino una manera de decir que el lenguaje humano posee una dimensión de realidad que sobrepasa en mucho su condición de mero instrumento o medio de comunicación, admitiendo, en cambio, que en él hay una poiesis de base, hecho que hace posible que la comunicación lingüística devenga poesía. Es decir, que aun en el uso recurrente, confuso y común del lenguaje, hay una voz poética, temporalmente acallada si se quiere, presta a hacerse presente en cuanto el hablante-poeta le dé espacio para el desborde, para la ruptura de "todo bando", según el decir de Novalis.

\section{EL DOMINIO POÉTICO DEL LENGUAJE}

En su clásico Curso de lingüística general, Saussure sostuvo:

Tomado en su conjunto, el lenguaje es multiforme y heteróclito; a caballo en diferentes dominios, a la vez físico, filosófico y psíquico, pertenece además al dominio individual y al dominio social; no se deja clasificar en ninguna categoría de los hechos humanos, porque no se sabe cómo embrollar su unidad (Saussure, 1972, p. 37).

A los dominios mencionados por Saussure habría que agregar el dominio poético, no en el sentido de que en determinados mensajes prevalezca la función poética tal como la describe Jackobson. ${ }^{3}$ En efecto, sospecho que la dimensión poética del lenguaje es más que la función poética de este; de hecho, no es una función poética en absoluto si por ello entendemos un añadido estético al lenguaje instrumental comunicativo. Prefiero pensar dicha dimensión como la condición instituyente del lenguaje en cuanto tal, de manera que la sola práctica lingüística, independiente de si es con fines estéticos o no, constituye en sí misma una práctica imaginativa que construye realidad con sentido humano, según las

\footnotetext{
${ }^{3}$ Ver el conocido ensayo de Roman Jackobson "Lingüística y poética" (1971), originalmente publicado en 1960, incluido en El lenguaje y los problemas del conocimiento, publicado en Buenos Aires en 1971, que recoge ensayos de lingüística y literatura de Jackobson, Barthes y otros.
}

246 | Alpha No50 (Julio 2020) PÁGS. 243-262. ISSN 07 16-4254 
posibilidades materiales de un idioma concreto en un momento histórico determinado. El lenguaje mismo es un hecho poético, en tanto no es un mero conjunto de signos unidireccionalmente asociados a un cierto conjunto de realidades extralinguísticas; que si así lo fuera este no pasaría de ser un instrumento solo informativo o denominativo de dichas realidades y se cancelaría la posibilidad de la polivalencia semántica.

Entonces, el lenguaje sí sería un código, y nada más que un código, dependiente por añadidura de las realidades extralingüísticas que entonces les exigirían a sus signos una literalidad absoluta. Hablar del mundo y hacer que este hable implica, sin duda, rendirse a la evidencia de que hay un mundo material extralingüístico - una especie de materia oscura que no necesita del lenguaje para estar ahí (aunque decir "no necesita" puede ser muy discutible)- del que se puede predicar solo aquellos atributos que están al alcance del lenguaje humano, de un idioma concreto para ser preciso. Pero este mismo planteamiento ya sugiere que los "alcances del lenguaje" son los "alcances del mundo" que nos tocan, nos interpelan, en la forma de enunciados lingüísticos poseedores de sentido.

En efecto, y siguiendo ahora a Walter Benjamin, diremos que aquello que está al alcance del lenguaje es precisamente la "entidad lingüística" de las cosas del mundo, entidad que no es equivalente a la totalidad de las cosas sino solo a aquello de las cosas que es comunicable con lenguaje humano. "El lenguaje comunica la entidad respectivamente lingüística de las cosas" (Benjamin, 2001, p. 61), afirma el pensador alemán. Y más adelante:

La entidad lingüística de los hombres es su lenguaje. Y esto significa que el ser humano comunica su propia entidad espiritual en su lenguaje. Pero el lenguaje humano habla en palabras. Por tanto, el hombre comunica su propia entidad espiritual, en la medida en que es comunicable, al nombrar las otras cosas (Benjamin, 2001, p. 62, itálicas mías).

El argumento de Benjamin toca terrenos lingüísticos, filosóficos y teológicos en un esfuerzo por elaborar una concepción no burguesa del lenguaje e interpelar, de paso, a la lingüística de su época para que considere que el lenguaje no es solo un medio de comunicación -sino un médium como dirá el propio Benjamin- ni un mero conjunto de signos convencionales y que están conectados de manera arbitraria con las cosas. "El lenguaje no ofrecerá jamás meros signos", afirmará de manera enfática Benjamin (2001, p. 68, cursivas del autor).

Sin pretender glosar a Benjamin, pero sí apoyándome en él, me gustaría proponer tres ideas fuerzas que contribuyan al despliegue de esta exposición respecto de "la poesía del lenguaje". La primera: el lenguaje humano no se define en su sola condición de sistema de signos de las cosas del mundo, si es que por esto entendemos el lenguaje como un puro artificio que representa y alude mecánicamente (vale el ejemplo del semáforo aquí), a un mundo no lingüístico, natural, a un allá afuera nunca afectado por los signos 
que lo nombran. $\mathrm{Al}$ revés, en el lenguajear humano las cosas llegan a nosotros, se hacen palabras, se manifiestan en la identidad linguística que ellas poseen.

El lenguaje transmite la entidad lingüística de las cosas. y la más clara manifestación de ello es el lenguaje mismo. La respuesta a la pregunta: ¿qué comunica el lenguaje?, sería: cada lenguaje se comunica a sí mismo. Por ejemplo, el lenguaje de esta lámpara no comunica esta lámpara (la entidad espiritual de la lámpara, en la medida en que es comunicable, no es de modo alguno la lámpara) sino la lámpara lingüística, la lámpara de la comunicación, la lámpara en la expresión (p. 61; itálicas del autor).

Una segunda idea arranca de la siguiente afirmación de Benjamin: "no existe evento o cosa, tanto en la naturaleza viva como en la inanimada, que no tenga, de alguna forma, participación en el lenguaje, ya que está en la naturaleza de todas ellas comunicar su contenido espiritual. Así usada, la palabra 'lenguaje' no es de modo alguno una metáfora" (p. 59). La realidad completa puede, entonces, concebirse organizada en lenguajes entretejidos; esto desde el momento en que accedemos a la escena en que las palabras se vuelven práctica de hacer sentido, es decir, trabajo destinado a hacer emerger resonancias semánticas que modelan, a menudo de modo inesperado y desafiante, el paisaje del mundo tanto como el de la conciencia del lenguaje vuelta sobre sí misma, hecho que nos pone de frente ante el ser, ante lo que somos y lo que no somos.

Asimismo, y como tercera idea, retengamos la aseveración de Benjamin de que "el lenguaje no solo significa comunicación de lo comunicable, sino que constituye a la vez "símbolo de lo incomunicable"" (p. 74), punto que me parece crucial para entender que "hacer sentido" es siempre una operación de selectiva reducción de posibilidades de significación, las que quedan determinadas por los atributos materiales de una lengua concreta; lengua que, de un modo u otro, modela a su amaño el paisaje del mundo, según su gramática, su léxico, sus mecanismos de composición textual, etc. Por lo mismo, toda práctica lingüística es al mismo tiempo la cancelación automática de aquellos lenguajes -en el sentido benjaminiano de "entidad lingüística" de las cosas- intraducibles a la lengua concreta en y con la que se realiza la práctica de producir sentido. Toda expresión es al mismo tiempo la imposibilidad de una expresión otra. Es en este sentido en que, estimo, habría que entender el aserto de Benjamin antes citado.

La tesis de Benjamin, de que las cosas poseen una entidad lingüística que se comunica - en lo que tiene de comunicable en el lenguaje que las nombra-, me lleva a pensar el lenguaje de los humanos como el acontecimiento primordial del ser y del existir de las cosas en la cultura; hecho a partir del cual estas, entre ellas el propio lenguaje, se manifiestan como tales a la conciencia humana. En el acontecimiento primordial del lenguaje están ya dadas las condiciones para la autoconciencia linguística, las que, a nivel de enunciados, se manifiestan en la forma de metatextos, literarios o no, que hablan del 
mundo, al mismo tiempo que hablan de cómo hablar del mundo y viceversa. Pero si es así (y estimo que así es en efecto), entonces habría que aceptar que el lenguaje es sobre todo autónomo en el sentido de que no es dependiente de las cosas que nombra; entendiendo por dependencia la condición de epifenómeno de las cosas. No es dependiente de las cosas - no como epifenómeno de estas al menos-, pero queda obligado a nombrarlas en cuanto a que su condición misma de lenguaje se concretiza justamente en la operación de nombrar el mundo y comunicarlo según las reglas de un idioma concreto y según las reglas de convivencia y entendimiento de una comunidad humana determinada cuyos miembros comparten dicho idioma. Y las nombra no porque las cosas posean nombres anteriores al lenguaje -ciertamente desde una perspectiva individual las cosas ya tienen nombre antes de que un individuo aprenda a hablar; de hecho, aprender a hablar es en principio aprender el nombre de las cosas-, sino porque el propio lenguaje genera las condiciones para que la entidad lingüística de las cosas emerja de suyo y se torne comunicable en el lenguaje. Desde esta mirada, el lenguaje es mucho más que un sistema lingüístico en el sentido saussureano del término, si bien no deja de ser un sistema, deviniendo práctica dialógica abierta a la historicidad, siempre en proceso, consustancial a la vida en sociedad de los hablantes de una determinada comunidad lingüística.

El lenguaje, entonces, podría verse como una suerte de entidad flotante a la que los sujetos se aferran para no hundirse en el caótico océano de un mundo despojado de lenguaje (un mundo imaginable pero no representable); $\mathrm{o}$, si se prefiere y para decirlo más o menos en los términos de Benjamin, un mundo imposibilitado de forma absoluta de que en él la entidad linguística de las cosas se torne comunicable. La imagen de la entidad flotante tal vez sea ilustrativa, pero no le hace justicia a la complejidad del asunto. El lenguaje no es solo una tabla a la que se aferran los náufragos de la realidad, en el tormentoso mar del existir, digamos: es la condición instituyente de la realidad toda en tanto esta se presenta y representa con sentido humano, incluido el propio sujeto hablante, que, en tanto tal, es sujeto en toda regla: multidimensional y complejo como son los seres humanos. Debido a su condición instituyente, el lenguaje es en sí mismo una práctica poética en la medida en que la práctica se concretiza en el trabajo -mental en primer término- de "producir" el mundo de acuerdo, como se ha dicho, con las posibilidades de significación propias del idioma de que se trate.

La idea de "producir" el mundo habría que entenderla en un sentido creador e instituyente de un mundo lingüístico que es al mismo tiempo psíquico, social, cultural, histórico, semiótico, poético. De manera que en su instancia productiva primordial, el lenguaje se nos aparece con una naturaleza paradójica: se muestra incapaz de hacerse cargo de la complejidad de las cosas del mundo en un sentido absoluto, por lo que cualquier enunciado sobre eso que casi siempre llamamos realidad nunca comunicará toda la realidad referida sino solo aquella que las palabras y sus reglas de combinación hacen posible, a lo que se añade, claro está, las perspectiva del hablante, su lugar de 
enunciación, la situación comunicativa en suma. Este mismo hecho, sin embargo, le concede al lenguaje la peculiar característica de "producir" el mundo a su medida ejerciendo su imperio lingǘstico sobre las cosas al punto tal que estas terminan siendo lo que de ellas se puede predicar. Cobra, pues, sentido urgente la idea de Hölderlin de que el lenguaje es el más peligroso de los bienes.

Quienes contamos con alguna experiencia en materia de escritura de poesía, sabemos muy bien cuánto debemos batallar para arrancarle al lenguaje sus más sutiles significaciones; para forzarlo a que nos hable en un registro cuya semántica singularmente densa le haga algo de justicia a una cierta imagen o visión de realidad -un sector de ella en rigor- que es, o pretende ser cuando menos, multidimensional y en la que han de caber e imbricarse lo conceptual, lo imaginario, lo emotivo, lo descriptivo. Se trata de dimensiones que en la poesía se hallan entretejidas, codificadas como una totalidad inseparable. Desde luego, no hay garantías de que de este tipo de práctica lingüística deriven siempre resultados óptimos. La verdad es que la mayoría de las veces los resultados dejan mucho que desear, asunto que los poetas viven a menudo como agudas experiencias de fracaso con el lenguaje; aunque también las hay de plenitud ciertamente.

La pretensión de lenguajear la totalidad de esa ventana de realidad que un texto poético despliega, está, sensu estricto, más allá de las posibilidades de expresión, significación y comunicación de esa misma realidad. La conciencia de que hay siempre una brecha insalvable entre lo dicho y lo referido por aquello que es dicho, acompaña siempre al poeta y lo mueve a explorar nuevas posibilidades expresivas. $\mathrm{Y}$ aunque semejante situación pueda imputarse a la incapacidad del poeta y no del lenguaje como tal, esto no cambia el hecho de que el lenguaje no garantiza a priori que siempre haga justicia a las complejidades del mundo y de la vida, en el entendido de que lo que se pretende es precisamente dar cuenta de esas complejidades. Pero, por otro lado, el hecho de que el lenguaje sea un bien social le abre al poeta la puerta a una dialógica recursiva, solidaria e historizada, de manera que un poeta no batalla nunca solo: en su hablar se inscriben las huellas de todos quienes son y han sido parte de la dialógica del lenguaje.

"Poetizar es engendrar. Todo lo poetizado ha de ser individuo viviente", asegura Novalis (2017, p. 12), afirmación que se condice con su tesis de que "para el poeta el lenguaje nunca es demasiado pobre, pero siempre es muy general" (p. 11). Si seguimos a Novalis, la poesía del lenguaje vendría a manifestarse como el despliegue de una energía creativa (que es a la vez descubridora), conducente a la conformación de experiencias de realidad, mediadas por el lenguaje, cuyo denominador común es la vivencia de una singularidad "viviente" que habita, por derecho propio, en la dimensión lingüística de las cosas, la que entonces se hace patente. De hecho, la poesía es uno de los modos de ser del lenguaje en el que la percepción (imaginaria) de que las cosas hablan en el lenguaje, se 
torna singularmente fuerte; tanto que se tiene la sensación de oír en el poema el vasto murmullo de las materias tangibles e intangibles del universo.

Se trata, si se quiere, del efecto producido por una cierta manera de componer un texto que apela a las convenciones de la poesía. Pero nada de esto sería posible si en el lenguaje mismo no estuviera ya el potencial creador que deriva de su condición de médium de la realidad (que incluye al propio lenguaje) tanto como de modelador de la misma por su naturaleza en última instancia imaginaria, proyectiva, instituyente de las cosas y los sujetos. Que a menudo un poeta requiera, como sugiere Novalis, "palabras recurrentes tomadas del uso" (p. 11) no ha de ser para repetir machaconamente lugares comunes, que por comunes ya no dicen nada singular, sino para hurgar en esas palabras la fuerza instituyente que las hacen únicas a la hora de elaborar una determinada singularidad poética. O sea, a la hora en que el lenguaje deja de ser caja de resonancia de estereotipos y generalidades que aplanan las, acaso, infinitas particularidades del relieve vasto del paisaje del mundo. Es en los estereotipos y generalidades por donde asoman de manera peligrosa los monocultivos del lenguaje que terminan siendo ¡cómo no! monocultivos de la mente ${ }^{4}$.

El lenguaje -escribe Heidegger- no es solo un instrumento que el hombre posee entre muchos otros; el lenguaje es lo que, en general, y ante todo, garantiza la posibilidad de encontrarse el hombre en medio de lo abierto del ser que está siendo. Solo allí donde hay lenguaje hay 'mundo', es decir, este círculo continuamente cambiante de decisión y empresa, de acción y responsabilidad, como también de arbitrariedad y de tumulto, de caídas y de extravíos. Y allí es donde hay 'mundo' hay Historia (Heidegger, 1944, p. 17).

Si donde hay lenguaje hay mundo, la naturaleza de ese mundo, su grandiosidad o miseria, estarán entonces ligadas al lenguaje que lo "produce", a la grandiosidad o miseria de este. Cuidar el lenguaje será entonces cuidar el mundo. Sabemos, por otra parte, que el mundo - la materia mundo- hace también al lenguaje; de manera que podríamos de igual modo invertir la afirmación de Heidegger: ahí donde hay mundo, hay lenguaje; tesis que nos pone en línea con el argumento de Benjamin, en cuanto que, según este pensador y como ya se citó antes, "no existe evento o cosa, tanto en la naturaleza viva como en la inanimada, que no tenga, de alguna forma, participación en el lenguaje" (Benjamin, 2001, p. 59). Dos consideraciones se pueden derivar de lo anterior:

1. Las experiencias de diversidad en el mundo material impactan sobre el lenguaje en cuanto que este queda "obligado" a diversificarse, a ampliar su repertorio de vocabulario y a inaugurar nuevas prácticas de enunciación. Se trata, claro, de un proceso de largo plazo que puede ser imperceptible a nivel de un hablante individual,

${ }^{4}$ Me apropio aquí de la expresión de Vandana Shiva (2008). Ver su libro Los monocultivos de la mente. AlPHA No 50 (Julio 2020) PÁGS.243-262. ISSN 07 16-4254| 251 
salvo quizás por la experiencia individual de sentir, de pronto, que se carece de palabras para designar realidades nuevas hasta ahora desconocidas. Las transformaciones del mundo material transforman el lenguaje; así, los objetos o situaciones que se vuelven anacrónicos o que pierden su vigencia y razón de ser, convertirán tarde o temprano en arcaísmos a las palabras que los nombran y a la larga quizás acontezca la total desaparición de esos nombres del repertorio lingüístico.

2. Pero el lenguaje a su vez impacta sobre el mundo material en tanto este último se torna en "mundo", en el sentido en que lo describe Heidegger, por el lenguaje y en el lenguaje. $\mathrm{O}$ sea, las transformaciones en el lenguaje redundan en modificaciones de sentido y representación que hacen que la realidad material de los cuerpos adquiera, digamos, una determinada aura lingüística que en rigor no es sino la entidad linguística de las cosas hecha presencia en las palabras que las nombran. La continuidad cambiante del devenir del lenguaje es la historia en curso del lenguaje, y en cierto modo esa historia en curso es, al mismo tiempo, la historia abierta de los modos de producción de sentido.

\section{PELIGRO Y PRECARIEDAD DEL LENGUAJE}

El lenguaje es parte de las materialidades mundanas que conforman nuestro mundo cotidiano. Aunque es al mismo tiempo aquello que hace posible que tales materialidades existan en cuanto tales ante la conciencia humana en la forma de palabras o enunciados con sentido. Esta doble condición le otorga al lenguaje un margen poderoso de autonomía, de libertad: fuente de sentido, mas también lugar de manipulación discursiva; máquina semiótica que condiciona el ser, su continuidad y hasta su eventual desaparición. "El adjetivo, cuando no da vida, mata", escribió con singular clarividencia el poeta Vicente Huidobro en 1916, en su célebre "Arte poética"5. Y tiene mucha razón: los adjetivos no solo califican las cosas; describen sus características o cualidades (reales o imaginarias) y son, por encima de todo, instancias lingüísticas que buscan generar, y a menudo lo consiguen, comunidad de sentimientos, de actitudes, de emociones, de posiciones ideológicas incluso entre el emisor y el receptor del mensaje. Este hecho lingüístico se puede tornar muy poderoso (y peligroso), cuando determinadas características se predican como atributos esenciales, inherentes, inamovibles y absolutos del sujeto, caso en que el verbo ser (o equivalente) opera como una cópula constructora de una identidad absoluta, total y natural del sujeto, desconociendo la dimensión imaginaria y móvil del lenguaje. Decir una barbaridad como que los indios no tienen alma, y, por tanto, no son del todo humanos es un aserto falso y éticamente insostenible;

\footnotetext{
${ }^{5}$ El poema “Arte poética” de Huidobro (2019a) forma parte de su libro Espejo de agua, de 1916. Cito el poema desde una versión en línea.

252 | AlPHA No50 (Julio 2020) PÁGS. 243-262. ISSN 07 16-4254
} 
pero en determinados contextos puede ser tan performativamente poderoso que llegue a mutar en aserto "verdadero". De hecho, así lo fue en la América colonial y hasta el siglo XIX al menos, de modo que esta "verdad" devino fundamento axiomático de políticas de esclavitud y exterminio de la población indígena. Es cierto que el lenguaje es un bien peligroso y a veces puede llegar a ser incluso perverso.

¿Se puede prevenir, contrarrestar, anular este peligro? Sí, aunque como sucede en el ámbito de la aceptación o denegación del otro, las convicciones éticas son las que tienen la última palabra. De todos modos, me atrevo a mencionar algunas estrategias que contribuyen a restar fuerza, si es que no a neutralizar del todo, el peligro de un lenguaje que de forma deliberada anula la necesaria y natural distancia entre las palabras y la cosas: historizar radical y críticamente la conciencia, elaborar y poner en práctica principios morales de manera genuina democráticos; hacer de la sospecha un principio orientador de las prácticas de recepción e interpretación de discursos; atender a la poiesis linguírstica y hacer de ella una práctica de desmitificación semántica que opere a modo de antídoto ante enunciados generales erigidos como presuntas verdades absolutas sintonizadas, a menudo, con instintos humanos primitivos (v. g., de territorialidad o de etnicidad excluyente). El fanatismo ideológico, por ejemplo, se podría comprender como una cadena de enunciados que expresan atributos totales a determinadas realidades (personas, cosas); de manera que no dejan espacio alguno a atributos alternos, salvo como rasgos o realidades que se tienen que anular o erradicar sin concesiones. Cierto que el fanatismo no es solo un hecho lingüístico, pero sí es en primer lugar un hecho lingüístico que puede producir una realidad muy real, muy material (no solo simbólica), cuando del lenguaje se pasa a acciones de aniquilación del otro, congruentes con sus fundamentos discursivos y doctrinarios.

Los idiomas, como la cultura, cambian constantemente. Poseen, diríamos, tanto la cualidad de expandirse, agregando, por ejemplo, nuevas palabras, como la de contraerse desactivando léxico y formas gramaticales que se vuelven entonces arcaicas o solo "muertas". Medidos en distancias de siglos o milenios, los idiomas mutan al punto de llegar a ser completamente otros en relación con su propio pasado, si es que no desaparecen por falta de hablantes. Constatar un hecho tan obvio como este, no tiene más objetivo que remarcar lo ya sabido: el lenguaje es una entidad dinámica, que se ajusta a los cambios de la realidad social y cultural; pero, al mismo tiempo, los cambios lingüísticos posibilitan la emergencia de nuevas semiosis que modifican, de un modo u otro, la misma realidad social y cultural en la que habita el lenguaje.

El lenguaje habita en la cultura y esta en el lenguaje. Es un hecho que cobra espesor dramático en tiempos de crisis, cuando determinados escenarios de sociedad se derrumban y los efectos a menudo desastrosos de estas implosiones se manifiestan en la forma de acciones tan bárbaras que vuelven insuficientes, si no anacrónicas del todo, los modos de significar el mundo que alguna vez gozaron de prestigio o de legitimidad. El horror, como la belleza sublime, es indecible en su literalidad absoluta. Y las metáforas a 
veces tampoco alcanzan para una representación que haga justicia a un referente que sobrecoge o avergüenza hasta el límite y aún más allá. Es lo que da a entender Adorno en su famoso pasaje acerca de la imposibilidad de escribir poesía después de Auchtwitz. ${ }^{6}$ Aunque, en verdad, no se trata de que no se pueda escribir poesía en absoluto después de Auchtwitz, sino de un pertinaz reclamo por una ética de la poesía: que en su lenguajeo simbólico esta asuma el indecible horror y no convierta en estética la memoria de las víctimas, so pena de ponerse del lado de los verdugos mediante una operación lingüística que termina, no obstante su aparente belleza, siendo cómplice del horror. En este sentido, los poetas tienen una responsabilidad mayor con el lenguaje: hacer que este no quede atrapado en convencionalismos instrumentales, en la machacona reiteración de lugares comunes. $\mathrm{O}$, peor aun, atrapado en sutiles y perversas constelaciones de discursos estéticos que diluyen, en beneficio del arte, de la interesada estetización de las cosas en rigor, las dramáticas realidades de la vida y la muerte, violentando los fundamentos mismos de la dignidad humana. Esto, por encima de si los poetas, en tanto sujetos civiles, son más liberales o más conservadores, por decirlo de modo esquemático. Se trata de algo más complejo que solo proclamarse fiel a una determinada ideología política, por ejemplo. La tarea será nada menos que restituir, con la poesía, la dañada "casa del ser"; de modo que el lenguaje vuelva a habitar un mundo lo más completo y total posible y no en un mero recorte ideológico enunciado con "bellas" palabras. Sabemos que, cuando la realidad por fuerza se la adscribe a un cierto modelo estético, los resultados pueden ser la perversión misma de lo estético al punto que se vuelve "cosa barbárica escribir un poema" (Adorno, 1962, p. 29).

El poeta chileno Vicente Huidobro, antes aludido, en uno de sus varios manifiestos escribió en 1921:

Aparte de la significación gramatical del lenguaje, hay otra, una significación mágica, que es la única que nos interesa. Uno es el lenguaje objetivo que sirve para nombrar las cosas del mundo sin sacarlas fuera de su calidad de inventario; el otro rompe esa norma convencional y en él las palabras pierden su representación estricta para adquiere otra más profunda y como rodeada de un aura luminosa que debe elevar al lector del plano habitual y envolverlo en una atmósfera encantada.

En todas las cosas hay una palabra interna, una palabra latente y que está debajo de la palabra que las designa. Esa es la palabra que debe descubrir el poeta (Huidobro, 2019b en línea).

"En todas las cosas hay una palabra interna", dice el poeta; afirmación que bien podría ser sostenida por el propio Benjamin. En las cosas hay una palabra interna; las cosas están organizadas como un lenguaje; las cosas son en el lenguaje. Más allá de que

\footnotetext{
${ }^{6}$ Ver "Discurso sobre poesía lírica y sociedad" en Obras citadas.

254 | AlPHa No50 (Julio 2020) PÁGS. 243-262. ISSN 07 16-4254
} 
el argumento de Huidobro esté al servicio de defender el creacionismo, movimiento estético de vanguardia del que él mismo se consideraba su fundador y mayor representante, importa aquí retener la idea de que el lenguaje funciona en más de una dimensión. Que, en efecto, el trabajo de la poesía no es decorar el decir humano con metáforas, sino "videnciar", si se me permite el verbo, las significaciones de alcance ontológico que el lenguaje comporta a la hora de tratar discursivamente con lo que Benjamin llama "la entidad lingǘística de las cosas". Se trata de algo que también puede verse como el trabajo de producir textos que registren la tarea poética, siempre en curso, de aprehender y significar la realidad en un sentido total: "el lector corriente -dirá Huidobro- no se da cuenta de que el mundo rebasa fuera del valor de las palabras [en cuanto inventario], que queda siempre más allá de la vista humana un campo inmenso lejos de las fórmulas del tráfico diario" (Huidobro, 2019b, en línea). Dicho de este modo, el lenguaje no solo es un bien peligroso, como anota Heidegger: es también un bien precario, que no alcanza a cubrir toda la realidad. El trabajo poético del lenguaje y con el lenguaje, consistirá entonces en arrancar al lenguaje de esa precariedad y volverlo verbo poderoso por la vía de correr los cercos de la representación; empresa sin garantías, sin embargo, aunque necesaria para que el lenguaje no languidezca tras las alambradas del "tráfico diario" o, lo que sería más trágico, tras los cercos de fanatismos e intolerancias que se manifiestan en la forma de discursos sostenedores de verdades absolutas.

\section{LA POESÍA COMO CONDICIÓN DE POSIBILIDAD DEL LENGUAJE}

Detenerse a meditar respecto de la tesis de que la "poesía empieza por hacer posible el lenguaje" podría ser, perfectamente, el trabajo de una vida entera empeñada en dilucidar la naturaleza última del lenguaje en su trato con esa entidad vasta que llamamos mundo. Es la tarea magna a la que nos invita Heidegger:

El dominio en que actúa la poesía es el lenguaje. La esencia de la poesía debe ser concebida por la esencia del lenguaje. En seguida hemos dicho cómo la poesía es la denominación fundadora del ser y la esencia de todas las cosas, en ninguna forma como un "decir" cualquiera, sino aquel decir por el cual todo se encuentra inicialmente puesto al descubierto, todo lo que nosotros debatimos y tratamos en el lenguaje de todos los días. En consecuencia, jamás la poesía recibe el lenguaje como un material de trabajo que le sería dado previamente, sino que, al contrario, la poesía empieza por hacer posible el lenguaje. La poesía es el lenguaje original de un pueblo. Es preciso, pues, que, inversamente, la esencia del lenguaje sea comprendida por la esencia de la poesía (Heidegger, 1944, p. 21).

Quisiera en esta ocasión compartir algunas consideraciones - provisionales como es de suponer-, que arrancan de lo que Heidegger propone y que espero contribuyan a pensar el lenguaje con el respeto que merece su naturaleza tan determinante para la 
condición humana. En primer lugar, solo si concebimos la poesía como una condición de posibilidad primordial para que acontezcan las significaciones del mundo, en y con el lenguaje, tendría sentido la afirmación de que "la poesía empieza por hacer posible el lenguaje". La poesía sería la energía originaria de las significaciones, de modo que el lenguaje, en tanto acontecimiento poético, se nos da como una creatividad productora de mundos humanos; vale decir, de una forma de relacionarnos con lo "otro" de "nosotros", hecho que se materializa como escena de representación que opera en un doble sentido: aprehendemos (y eventualmente comprendemos) lo que las cosas son para nosotros y lo que nosotros somos para las cosas. Producir mundos es, pues, también producir subjetividades, hacer que los cuerpos se tornen sujetos en el lenguaje y gracias a él, para ello el lenguaje dispone de recursos, empezando por los pronombres y continuando con todo su tinglado léxico-gramatical que, por otra parte, no cesa de transformarse no obstante su igualmente necesaria estabilidad.

Así, la poesía, en tanto género literario, con sus reglas, sus modelos retóricos, sus exigencias, su tradición, en fin, con todo lo que en un momento dado conforma el campo literario de la poesía, no sería sino la versión concentrada y decantada del ser del lenguaje; ser que, por lo pronto, me atrevería a describir como práctica dialógica de producir e intercambiar significaciones. Se trata, ciertamente, de un genuino acontecimiento cultural, en la medida en que dicha práctica es constitutiva de la cultura misma; práctica animada por las energías del pensar, del sentir, del percibir, del imaginar, del recordar, las que operan sobre los cuerpos y los objetos "puramente materiales", desplazándolos a la condición de entidades "espirituales", para decirlo en terminología de Benjamin. Es decir, convirtiendo a estos cuerpos y objetos "puramente materiales" en personajes que tienen lugar y sentido en la escena del sujeto, negociando su condición subjetiva con la dimensión significativa de todo lo que deviene objeto para dicho sujeto, incluido él mismo. Esta potencia creativa del lenguaje es la poesía; fuente de energías semióticas que mueven y terminan conformando nada menos que la escena completa de la cultura. Asimismo, la poesía, en su condición de género textual específico, opera como una máquina en especial diseñada para hacer del lenguaje un médium por donde habla el mundo. Es en la poesía donde el lenguaje, desligado de sus urgencias puramente comunicacionales (en el sentido de inventario, como acota Huidobro), o de los constreñimientos ideológicos que lo empujan a ser reductoramente funcional a un fin instrumental, se vuelve otra vez fundacional; retorna, diríamos, a la primigenia tarea de que el mundo se presente como si fuera la primera vez que está ahí delante de una asombrada conciencia.

Se podrá decir, con justa razón, que la poesía también tiene fines comunicacionales, que no está al margen de determinaciones ideológicas, que el efecto de asombro y extrañeza no es un asunto que esté garantizado siempre y para todos en los textos calificados como poesía. Es efectivamente así; pero aquí importa atender al hecho de que la poesía es, por encima de todo, un ejercicio de producción textual comprometido primero y antes que todo 256 | ALPHA No50 (JuLIO 2020) PÁGS. 243-262. ISSN 07 16-4254 
con el lenguaje. Que es a partir de este compromiso de base que cobran sentido los demás compromisos (con la historia, con la naturaleza, con determinadas situaciones humanas, etc.). En este sentido, la poesía es el lenguaje trabajando sobre sí mismo, drenándose de las impurezas que lo esclerotizan. Asimismo, es en este sentido que habría que entender la afirmación de Heidegger (1944) en cuanto que la poesía es un "decir por el cual todo se encuentra en principio descubierto, todo lo que nosotros debatimos y tratamos en el lenguaje de todos los días" (p. 21). Si la poesía es poner en práctica, en la forma de poema, por ejemplo, la memoria fundacional del lenguaje, entonces la poesía será la condición necesaria para que las palabras del diálogo cotidiano no se vuelvan signos muertos, ajenos a los ríos invisibles de la vida que no cesan de fluir.

Empero, ¿cómo entender la idea de que la poesía es poner en práctica la memoria fundacional del lenguaje? Si pensamos el lenguaje como poesía, vale decir, como la energía originaria que crea y moviliza significaciones que nos vuelven seres dotados de lenguaje precisamente, o sea, en condiciones de tratar con la entidad lingüística de las cosas, no estaría fuera de lugar suponer que la poesía es el modo que tiene el lenguaje de resguardar su capacidad de renovar de manera constante la relación simbólica entre las palabras y las cosas. De modo que, sin que cada término deje de ser lo que es, al mismo tiempo cada uno se desdibuje en beneficio del otro; tanto que, imaginativamente al menos, lleguen a conformar una unidad indisoluble. Desde esta perspectiva, la expresión "memoria fundacional del lenguaje", es una manera de decir que la poesía es el ejercicio de trasladar al lenguaje a un ámbito en el que este se ocupe de elaborar escenas de significación, en las que el mundo aparezca con una saludable novedad y extrañeza ante nuestra conciencia y sensibilidad. Es, pues, en la poesía donde el lenguaje aparece mostrando su enorme potencia para producir mundos que no se agotan en su sola designación, a modo de inventario de estos. Al mismo tiempo, es aquí donde también el lenguaje hace evidente su precariedad, su imposibilidad de abrazar la totalidad del existir en cuanto que el lenguaje, al volverse sobre sí mismo, hace patente sus propias limitaciones y su ardua lucha por franquearlas o desplazarlas cuando menos.

Producir mundos con la poesía del lenguaje (que hace posible el lenguaje de la poesía), es en realidad producir experiencias de realidad, mediadas por el lenguaje, signadas por el hecho de que estas experiencias lo son de una realidad en estado tal, que solo existe en el lenguaje que recorre los meandros de la subjetividad. Tanto así, que esta subjetividad se ve impelida a vivir el mundo evocado por el lenguaje, como si en esta vivencia aconteciera la cancelación absoluta del tiempo y la muerte. Cuando se despliega la poesía del lenguaje, experimentamos en nosotros la posibilidad escenificada en el lenguaje -utópica en términos de realidad material extralingüística, pero real en términos de discurso que la representa y nos interpela-, de ser otros ante nosotros mismos y ante el mundo que entonces también será otro, debido a los desplazamientos imaginativos del sujeto y de su(s) identidad(es). 
$\mathrm{Al}$ poder evocador y convocante de la poesía, no hay que buscarlo solo en las formas lingǘsticas y en el estilo propio del poeta, si es que la mirada se detiene exclusivamente en la superficie textual en la que se hacen visibles determinadas técnicas poéticas. Estimo que sería más productivo, por lo menos para la perspectiva de lectura y meditación que he tratado de delinear aquí, ver el texto poético como la codificación de las energías creativas del lenguaje que se manifiestan y operan en varios niveles. Desde los enunciados en la forma de metáforas e imágenes analizables desde una perspectiva puramente lingüística (fonética, gramatical, semántica), hasta la figuración imaginativa de mundos sorprendentes que habitan en la cotidianidad en que vivimos y que el lenguaje -su poesía en rigor-nos devela. La poesía del lenguaje poco o nada tiene que ver con la verdad, si por verdad entendemos la simple adecuación entre un enunciado y su referente tomado este como algo que existe por sí y ante sí, en el afuera del lenguaje. Sí tiene que ver con la verdad, aquella que se presenta en la forma de significaciones complejas que nos invitan a ser partícipes de la fiesta de las palabras hacedoras del mundo y que evocan una epifanía de sentido. Digamos: la revelación de una cierta plenitud del ser-decir que bien puede tener la forma de una emocionante simplicidad que ni afirma ni niega, como la que nos brinda Jorge Teillier, poeta atento como pocos a la grandiosidad que habita en la pequeñez de lo cotidiano y hogareño:

palabras, palabras - un poco de aire

movido por los labios- palabras

para ocultar quizás lo único verdadero:

que respiramos y dejamos de respirar ${ }^{7}$.

\section{LA POESÍA DEL LENGUAJE. CIERRE PROVISIONAL}

Pensar el lenguaje como poesía arranca de mi sempiterna resistencia a concebir el lenguaje básicamente (si es que no de modo exclusivo) como instrumento de comunicación. En los comienzos de mi carrera como profesor universitario, y por varios años, me correspondió dictar cursos de comunicación lingüística que tenían una finalidad sobre todo práctica. La finalidad era enseñar, a los estudiantes, técnicas de composición textual que aseguraran una comunicación óptima, inequívoca y con el máximo posible de economía linguística. Se trataba de disponer el léxico, la gramática y el estilo de manera tal que la intención comunicativa del emisor llegara al receptor sin distorsión alguna, asumiendo, claro, que el emisor sabía "exactamente" lo que quería comunicar. El examen de los textos producidos demostraba, con frecuencia, que solía haber severas

\footnotetext{
${ }^{7}$ Versos finales del poema “Despedida", publicado originalmente en el libro El árbol de la memoria, 1961; incluido también en Los dominios perdidos, 1992.
} 
discrepancias entre lo que el texto "realmente" decía y lo que el emisor había pretendido decir en el mismo. Poco a poco los estudiantes aprendían que el texto, antes de existir, no está en la cabeza de quien lo compone (de quien lo escribe o lo habla), sino que la escritura misma crea una realidad nueva en la psiquis y en el entorno dialógico de la comunidad de hablantes. La complejidad asertiva de esa realidad nueva dependerá de cuán eficiente se apropie el hablante del lenguaje a la hora de comunicar y significar el mundo con el que negocia el texto.

Que el lenguaje es un medio de comunicación está fuera de duda. En efecto, producir mensajes comunicativamente eficientes y eficaces es un asunto más que necesario en la vida humana cotidiana. Asimismo, conocer un cierto conjunto de técnicas de la comunicación lingüística, le otorga al hablante que las domina una cierta ventaja práctica al momento de utilizar el lenguaje y hasta un estatus mayor por sobre quienes no están familiarizados con dichas técnicas. Con mis alumnos de entonces aprendí algunas cosas: a) Producir un texto gramatical y estilísticamente óptimo, en el que predomine el significado literal de las palabras, puede llegar a ser tan o más trabajoso que escribir un poema estéticamente bien logrado; no hay, pues, un lenguaje específico que se pueda calificar de "natural". b) La semántica del lenguaje no es ni "naturalmente" denotativa ni "naturalmente" connotativa; de modo que producir textos en los que predomine una forma de semanticidad por sobre otra implica un trabajo con y sobre el lenguaje. Equivale a ejercer una suerte de violencia sobre las palabras y las cosas para que estas se "ensamblen" dentro de determinadas reglas textuales. c) La función comunicativa del lenguaje, en el sentido de ser medio con el que se transmiten (o se busca transmitir) mensajes unívocos de punto a punto, viene a ser solo una de sus notas distintivas del lenguaje y no su rasgo primordial, rector, del que todos los demás serían derivaciones.

Hablar de la "poesía del lenguaje" es, claro está, una manera poética, si se quiere, de insistir en el hecho de que el lenguaje tiene la capacidad de revelar / descubrir (y por esto mismo producir) el mundo, de modo que este último se vuelve "casa del ser" habitada por el humano parlante, como lo sugiere Heidegger (1944): "la poesía es la fundación del ser por la palabra", afirmará enfático el filósofo (p. 19). Lo que tal vez sorprenda, es que esta "casa del ser" es tanto de lenguaje como de cosas: cosas que el lenguaje transforma en tales ante la conciencia humana. Así visto, el lenguaje no es propiamente signo del mundo, si es que esta fórmula supone la existencia dada del mundo como una entidad anterior al lenguaje y ante el cual el lenguaje no sería sino un artificioso, aunque complicado, sistema de signos y símbolos que codifica el mundo, del mismo modo como el lenguaje actual de la computación codifica determinadas acciones y procesos. Defiendo la idea de que el lenguaje, más bien, es signo del mismo lenguaje, es decir, signo de su propio trabajo de significar el mundo, y es en ese trabajo y gracias a él que comprendemos el mundo al punto de decirlo con palabras, si bien el mundo que decimos con palabras está muy lejos de ser la totalidad absoluta de lo que existe. 
Asimismo, hablar de "poesía del lenguaje" equivale aquí a ver en el lenguaje una especie de energía viviente capaz de hacer brotar el mundo por el hecho de que este es insuflado por la poesis autocreativa de lenguaje. Desde esta perspectiva, si el lenguaje es un código, lo que codifica son las reglas de emergencia y despliegue de la entidad lingüística de las cosas, que entonces pasan a ser lenguaje. Pasan estas a ser lenguaje en una doble condición: como referentes de las palabras y como condición de posibilidad de la existencia misma del lenguaje, el que, bien o mal, recoge en su seno la gramática, el discurso y el decurso del mundo. Desde este último punto de vista, la gramática del lenguaje es, al mismo tiempo, la gramática de las cosas en tanto entidades lingüísticas. Pero, a la vez, las cosas son entidades linguiísticas porque el lenguaje las hace tales.

La poesía del lenguaje hace posible la poesía con el lenguaje. El trabajo de los poetas es de primerísima importancia, si se trata de hacer que la energía viviente del lenguaje circule por las intersubjetividades en diálogo. Los poetas, sugiere Heidegger, son los guardianes del lenguaje en tanto morada donde habita/es el hombre: "Pero que esto [el ser puesto al descubierto por la palabra] permanezca, he aquí lo que se ha "confiado para cuidado y servicio de aquellos que actúan como poetas", dirá Heidegger, haciendo suyo un verso de Hördelin (1944, p. 19). Tal vez sea una tarea demasiado pesada para los poetas, quienes, después de todo, se acercan más a la figura de artesanos del lenguaje, que a la de guardianes o vates tocados por la vara de los dioses. Como fuere, la poesía, en tanto género literario, cabe ser vista como la cuidada magnificación y complejización de la natural condición poética del lenguaje; su práctica viene a ser un trabajo riguroso del lenguaje consigo mismo y con el mundo que redunda en una concentración de energía contraria al desgaste de las significaciones. La poesía es, se podría decir, la evidencia empírica de que el lenguaje instituye imaginativa y simbólicamente el mundo en el que habita el propio lenguaje, en la medida en que en ella lo hallamos de forma rigurosa ocupado de sí mismo, para, desde y con esa ocupación, consagrarse a las realidades de la vida transformadas en poderosas escenas líricas donde los lectores se sienten arropados por las palabras.

El lector de estas notas seguramente constatará que a lo largo de ellas no he dicho nada que de una u otra manera no se haya dicho antes. De manera deliberada he obviado bibliografía actual y he preferido, en cambio, hacerme acompañar por la voz de un reducido grupo de pensadores, lingüistas y poetas a estas alturas canónicos y fundacionales. Hallo en ellos la frescura de las fuentes primarias de la meditación, más que del árido análisis técnico. No quisiera ocultar, tampoco, el hecho de que estas notas arrancan de mi propia experiencia como escritor de poesía; poesía que, como dice Novalis, desordena-y en buena hora- todos los bandos. Entiéndase este escrito, también, como una invitación a no conformarnos con aproximaciones en exceso estáticas y reductoras acerca del lenguaje. Y sea a la vez un reconocimiento respetuoso a ese desconocido que llamamos lenguaje (en expresión de Julia Kristeva), que nos hace 
humanos en cuanto sujetos de historia y cultura ${ }^{8}$. Nos hace, asimismo, sujetos conscientes de la totalidad (inabarcable) del ser y sus límites, aunque esa conciencia, en su forma más radical, no sea sino un lenguajeo, o un balbuceo metafórico, incluso, cuya verdad nunca será literal, aunque sí congruente con unos cuantos hechos esenciales del ser: que existe, que deja de existir, que en el intertanto no cesa de aspirar a la felicidad, a la plenitud.

Cierro estas notas con versos de Hölderlin precisamente, en los que invoca a las Parcas, los mismos que Julio Cortázar coloca a modo de epígrafe al inicio de su bellísimo libro Imagen de John Keats:

Solo pido un verano, ¡oh poderosas!

y otro otoño para que madure mi canto

y más conforme, colmado por ese juego,

mi corazón se resigne a morir (1996).

\section{OBRAS CITADAS}

Adorno, Theodor (1962). "La crítica de la cultura y la sociedad". Prismas. Crítica de la cultura y la sociedad. Trd. Manuel Sacristán. Barcelona: Ariel, 9-29.

Benjamin, Walter (2001). "Sobre el lenguaje en general y sobre el lenguaje de los humanos". Para una crítica de la violencia y otros ensayos. Iluminaciones IV. Trad. Roberto Blatt. Madrid: Taurus, 59-74.

Cortázar, Julio (1996). Imagen de John Keats. Madrid: Alfaguara.

De Saussure, Ferdinand (1972). Curso de lingüística general. Trad. Amado Alonso. Buenos Aires: Losada.

Heidegger, Martin (1944). "Hölderlin y la esencia de la poesía". Trad. M. Bergmann y Cayetano Betancour. Revista Universidad Pontificia Bolivariana. V. 11, N 38:13-25.

Huidobro, Vicente (2019a). "Arte poética". Retablo de Literatura Chilena [en línea]. Disponible en: https://www.vicentehuidobro.uchile.cl/poema6.htm [consultado el 13-5-2019].

_ (2019b). "La poesía". Retablo de Literatura Chilena [en línea]. Disponible en: https://www.vicentehuidobro.uchile.cl/poema6.htm [consultado el 13-5-2019].

Jackobson, Roman; Roland Barthes et al (1971). El lenguaje y los problemas del conocimiento. Buenos Aires: Rodolfo Alonso.

Kristeva, Julia (1988). El lenguaje, ese desconocido. Introducción a la lingüística. Trad. María Antoranz. Madrid: Fundamentos.

${ }^{8}$ Ver El lenguaje, ese desconocido. Introducción a la lingüística de Julia Kristeva (1988). AlPHA No 50 (Julio 2020) PÁGs.243-262. ISSN 07 16-4254| 261 
Maturana, Humberto (1995, V.1; 1996, V.2). La realidad, ¿objetiva o construida? Fundamentos biológicos de la realidad. México: Universidad Iberoamericana, Anthropos.

Neruda, Pablo (2014). "Sobre una poesía sin pureza". Viaje al desbordante barroco (blog), septiembre 7, 2014 [en línea]. Disponible en:

https://viajealdesbordantebarroco.blogspot.com/2014/09/reflexion-proposito-desobre-una-poesia.html [consultado el 13-5-2019].

Novalis (2017). Fragmentos y anotaciones sobre poesía y filosofía. Trad. Nicolás Trujillo Osorio. Santiago. Cuadro de Tiza.

Shiva, Vandana (2008). Los monocultivos de la mente. Madrid/México: Fineo. 